\title{
Methotrexate-Encapsulating Autologous Tumor-Derived Microparticles
}

National Cancer Institute

\section{Source}

National Cancer Institute. Methotrexate-Encapsulating Autologous Tumor-Derived

Microparticles. NCI Thesaurus. Code C125656.

A suspension of autologous tumor-derived microparticles (ATMP), that are harvested from a patient with malignant pleural effusion, encapsulating the antimetabolic drug methotrexate (MTX), with potential anticancer activity. Although the exact mechanism(s) of action through which this agent exerts its effect has yet to be fully elucidated, upon administration of MTX-ATMP, the MTX moiety is released and internalized by tumor cells. It then binds to and inhibits the enzyme dihydrofolate reductase. This results in the inhibition of purine nucleotide synthesis and leads to decreased synthesis of both DNA and RNA, which induces cell death. Presumably, the encapsulation of MTX by the ATMP improves its bioavailability and decreases its toxicity. 